\title{
KARAKTERISASI FORMULASI EMULSIFIABLE CONCENTRATE (EC) INSEKTISIDA DELTAMETRIN
}

\section{CHARACTERIZATION OF FORMULATION OF DELTAMETHRIN INSECTICIDE EMULSIFIER CONCENTRATE}

\author{
Siti Raudhatul Kamali \\ Program Studi Kimia, Fakultas Matematika dan Ilmu Pengetahuan Alam, Universitas Mataram. \\ Jalan Majapahit No 62 Mataram, 83125, Indonesia \\ Email: sitikamali@gmail.com
}

Diterima: 11 Februari 2018. Disetujui: 22 Maret 2018. Dipublikasikan: 31 Maret 2018

\begin{abstract}
Abstrak: Deltametrin [(S)- $\alpha$-cyano-(3-phenoxypheyl)-methyl-3-(2,2-dibromovinyl)-2,2-dimethylcyclopropane carboxylate] sudah digunakan secara luas untuk pengendalian hama. Penelitian ini bertujuan untuk melakukan karakterisasi terhadap formulasi Emulsifiable Concentrate (EC) insektisida deltametrin. Formulasi ini menggunakan surfaktan Tween 80 dan ko-surfaktan Poli Etilen Glikol (PEG) 400 dengan perbandingan 20\%: $80 \%$. Morfologi Emulsifiable Concentrate ditentukan menggunakan mikroskop optik dan konfirmasi struktur molekul menggunakan FTIR. Nilai Hydrophylic-Lipophylic Balance (HLB) yang dihasilkan dari kombinasi surfaktan dan ko-surfaktan sebesar 13,48. Ukuran rata-rata diameter droplet yang dihasilkan sebesar $1 \mu \mathrm{m}$. Karakterisasi FTIR menunjukkan bahwa proses emulsifikasi deltametrin menjadi Emulsifiable Concentrate (EC) tidak mengubah bahan aktif deltametrin. Gugus $\mathrm{C}=\mathrm{N}$ yang merupakan gugus utama pada deltametrin muncul pada puncak $2259,64 \mathrm{~cm}^{-1}, \mathrm{C}-\mathrm{Br}$ pada $530,73 \mathrm{~cm}^{-1}$ dan regang $\mathrm{C}=\mathrm{O}$ aromatik pada $1715,85 \mathrm{~cm}^{-1}$.
\end{abstract}

Kata kunci: Insektisida Deltametrin, Emulsifiable Concentrate (EC)

\begin{abstract}
Deltamethrin [(S)- $\alpha$-cyano-(3-phenoxypheyl)-methyl-3-(2,2-dibromovinyl)-2,2 dimethylcyclopropane carboxylate] has been widely used to control pests. This research was conducted to characterize deltamethrin insecticides in Emulsifiable Concentrate (EC) formulation. This formulation used Tween 80 surfactant and Poly Etylene Glycol (PEG) 400 cosurfactant with combination of $20 \%: 80 \%$. The morphology Emulsified Concentrate was characterized by an optical microscope, meanwhile molecular structure was confirmated by FTIR. Lipophylic Hydrophylic Balance (HLB) value of 13.48 was resulted by surfactant and cosurfactant combination. The average size diameter of droplet produced $1 \mu \mathrm{m}$. The FTIR characterization showed that deltamethrin active ingredient in emulsifiable Concentrate (EC) formulation did not changed by emulsification process. Group of $\mathrm{C}=\mathrm{N}$ appeared at $2259.64 \mathrm{~cm}^{-1}, \mathrm{C}-\mathrm{Br}$ was observed at $530.73 \mathrm{~cm}^{-1}$ and $\mathrm{C}=\mathrm{O}$ aromatic stretch at $1715.85 \mathrm{~cm}^{-1}$.
\end{abstract}

Keywords: Deltamethrin Insecticides, Emulsifiable

\section{PENDAHULUAN}

Deltametrin

$[(\mathrm{S})-\alpha-$ cyano- $(3-$ phenoxypheyl) methyl 3-(2,2-dibromovinyl)-2,2dimethylcyclopropane carboxylate] merupakan insektisida non sistemik racun perut dan kontak, spektrum luas, dan termasuk golongan piretroid sintetik yang efektif untuk pengendalian hama [1]. Deltametrin berupa bubuk kristal berwarna putih dengan berat molekul 505,206 g/mol dan memiliki 4 akseptor ikatan hidrogen [3], memiliki gugus $\alpha$ siano pada 3-fenoksi benzil aklohol [4]. Struktur molekul deltametrin dapat dilihat pada Gambar 1.

Deltametrin bersifat sukar larut dalam air. Kelarutan dalam air sebesar $<0,002 \mathrm{mg} / \mathrm{L}$ pada suhu $25^{\circ} \mathrm{C}$. Sebaliknya pada suhu $20^{\circ} \mathrm{C}$, deltametrin memiliki kelarutan yang tinggi pada pelarut organik seperti; sikloheksanon $750 \mathrm{~g} / \mathrm{L}$, diklrometana 700 $\mathrm{g} / \mathrm{L}$, aseton $500 \mathrm{~g} / \mathrm{L}$, benzene $450 \mathrm{~g} / \mathrm{L}$, dimetil sulfoksida $450 \mathrm{~g} / \mathrm{L}$, silena $250 \mathrm{~g} / \mathrm{L}$, isopropanol 6 g/L [3]. Sukar larutnya deltametrin dalam air menyebabkan perlunya suatu formulasi yang tepat supaya bahan aktif insektisida ini bisa diaplikasikan secara mudah oleh petani menggunakan pelarut air.<smiles>CC1(C)C(C=C(Br)Br)C1C(=O)O[C@@H](C#N)c1cccc(Oc2ccccc2)c1</smiles>

Enantiomer $(\mathrm{S}) ;(1 \mathrm{R}, 3 \mathrm{R})=(\mathrm{S}) ;(1 \mathrm{R})$-cis

Gambar 1. Struktur Molekul Deltametrin [1]

Deltametrin dapat diformulasikan dalam produk insektisida sebagai aerosol, semprotan, debu, butiran, dan bubuk basah [7]. Di bidang pertanian, formulasi Emulsifiable Concentrate (EC) merupakan formulasi yang sangat populer di kalangan pengendalian hama. Formulasi ini diharapkan dapat mengurangi jumlah pestisida yang 
digunakan namun memberikan hasil maksimal terhadap OPT sasaran sehingga dapat mengurangi residu pestisida deltametrin di tanaman maupun lingkungan. Deltametrin memiliki spektum luas sebagai racun kontak dan racun perut, terutama pada golongan ortohoptera, thysanoptera, homoptera, dipteral, coleopteran, Lepidoptera, hymenoptera, serta terhadap kutu dan tungau [11]. Namun, residu deltametrin di lingkungan, apabila terpapar ke manusia dapat mengakibatkan gangguan kesehatan seperti sakit perut, mual, muntah-muntah, diare, hingga gejala keracunan berat seperti kerusakan ginjal, hati, dan paru-paru [10]

Formulasi Emulsifiable Concentrate (EC) dibuat dengan menambahkan emulsifier pada campuran bahan aktif dan pelarut agar dapat bercampur dengan air. Emulsifier dibutuhkan sebagai bahan penolong untuk membentuk emulsi dan berfungsi menstabilkan bahan aktif dalam air atau minyak yang diemulsikan. Kombinasi surfaktan dan ko-surfaktan merupakan emulsifier yang baik untuk pembentukan emulsified $\mathrm{o} / \mathrm{w}$. Emulsi $\mathrm{o} / \mathrm{w}$ terdiri atas droplet minyak yang dikelilingi oleh lapisan antarmuka tipis yang terdiri dari molekulmolekul emulsifier, terdispersi dalam fase kontinyu yang aqueous [5]. Salah satu faktor penentu kestabilan emulsi adalah Hydrophylic-Lipophylic Balance (HLB). Penentuan HLB merupakan cara untuk mencari jenis emulsifier yang akan bekerja terbaik dengan fase minyak dalam pembentukan emulsi [2]. Pada penelitian ini digunakan surfaktan Tween 80 dan ko-surfaktan Poli Etilen Glikol 400 (PEG) untuk mengembangkan suatu formula Emulsified Concentrate pestisida yang stabil. Telah diketahui bahwa interaksi antara $\mathrm{MBJH}$ dengan Tween 80 dan interaksi antara Tween 80 dengan PEG 400 memberikan koefisien bernilai positif, menunjukkan bahwa interaksi akan meningkatkan nilai waktu emulsifikasi [9].

\section{METODE PENELITIAN}

Bahan yang digunakan adalah deltametrin (Sigma Aldrich), Tween 80 pa (Merck), Poli Etilen Glikol (PEG) 400 pa (Merck), Aseton pa (Merck), Aquades (CV. Laborakarya). Alat yang digunakan adalah peralatan gelas, magnetic stirrer, Mikroskop optik, dan spektrofotometer FTIR

Formulasi Emulsifiable Concentrate (EC) berbahan aktif insektisida deltametrin dilakukan menggunakan kombinasi surfaktan Tween 80 dan ko-surfaktan Poly Etilen Glikol (PEG) 400. Perbandingan Tween 80 dan PEG 400 adalah 20:80. Surfaktan Tween 80 dilarutkan menggunakan aquades sedangkan PEG 400 dilarutkan menggunakan diklorometan. Bahan aktif insektisida deltametrin ditambahkan ke dalam larutan kosurfakan. Kemudian diaduk sampai homogen dengan magnetic stirrer dengan kecepatan 500 rpm selama 10 menit. Setelah itu ditambahkan larutan surfaktan tetes demi tetes sambil diaduk dengan magnetic stirrer dengan kecepatan 500 rpm hingga terbentuk sistem emulsi.

Sistem emulsi yang telah terbentuk selanjutnya dilihat morfologi partikel/droplet menggunakan mikroskop optik dan karakterisasi struktur molekul secara kualitatif dilakukan menggunakan spektrofotometer FTIR.

\section{HASIL DAN PEMBAHASAN}

Tipe dan Morfologi Emulsifiable Concentrate (EC)

Pada pembuatan Emulsifiable Concentrate (EC), dibutuhkan emulsifier untuk menjaga stabilitas emulsi. Pemilihan Emulsifiable Concentrate $(E C)$ disesuaikan dengan tipe emulsi yang diinginkan. Penentuan tipe emulsi didasarkan pada perhitungan nilai Hydrophylic-Lipophylic Balance (HLB). Nilai HLB merupakan angka yang menunjukkan ukuran keseimbangan antara gugus hidrofilik dengan gugus lipofilik, dimana gugus hidrofilik suka air atau polar sedanangk gugs lipofilik suka minyak atau non polar. Pada formulasi Emulsifiable Concentrate (EC) ini akan dibuat tipe emulsi tipe o/w, sehingga untuk mendapatkan tipe emulsi ini dibutuhkan nilai HLB 8-18 [2]. Formulasi Emulsifiable Concentrate (EC) insektisida deltametrin dilakukan menggunakan kombinasi emulgator yakni surfaktan Tween 80 yang memiliki nilai HLB 15 dan PEG 400 dengan nilai HLB 13,1 dengan perbandingan 20\%: $80 \%$. Kombinasi emulgator ini menghasilkan tipe emulsi o/w dengan nilai HLB 13,48 berdasarkan persamaan (1).

$$
H L B=\frac{W_{A} x H L B_{A}+W_{B} x H L B_{B}}{W_{A}+W_{B}}
$$

dimana, HLB = nilai HLB tipe emulsi; $\mathrm{W}_{\mathrm{A}}=$ jumlah emulsifier $\mathrm{A} ; \mathrm{W}_{\mathrm{B}}=$ jumlah emulsifier $\mathrm{B} ; \mathrm{HLB}_{\mathrm{A}}=$ nilai $\mathrm{HLB}$ emulsifier $\mathrm{A} ; \mathrm{HLB}_{\mathrm{B}}=$ nilai $\mathrm{HLB}$ emulsifier B

Tween 80 dan Poli Etilen Glikol (PEG) 400 merupakan surfaktan dan kosurfaktan non ionik. Keduanya berfungsi sebagai emulsifier, agen pelarut, dan pembasah. Tween 80 tidak memiliki muatan pada gugus hidrofobiknya, sehingga permukaan droplet deltametrin yang diselimuti oleh surfaktan ini cenderung tidak bermuatan. Tween 80 dan Poli Etilen Glikol (PEG) 400 tidak mudah dipengaruhi oleh kondisi asam maupun elektrolit sehingga tetap aktif sebagai lapisan permukaan antara deltametrin dengan air [9]. Hal ini dapat dilihat degan jelas pada perbedaan morfologi bahan aktif insektisida deltametrin murni dengan bahan aktif insektisida deltametrin dalam bentuk Emulsifiable Concentrate (Gambar 3). 


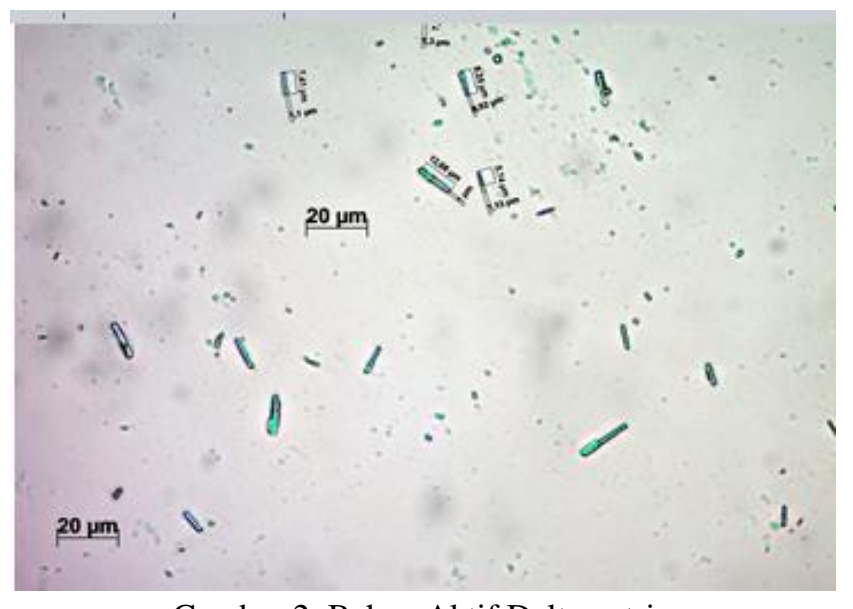

Gambar 2. Bahan Aktif Deltametrin

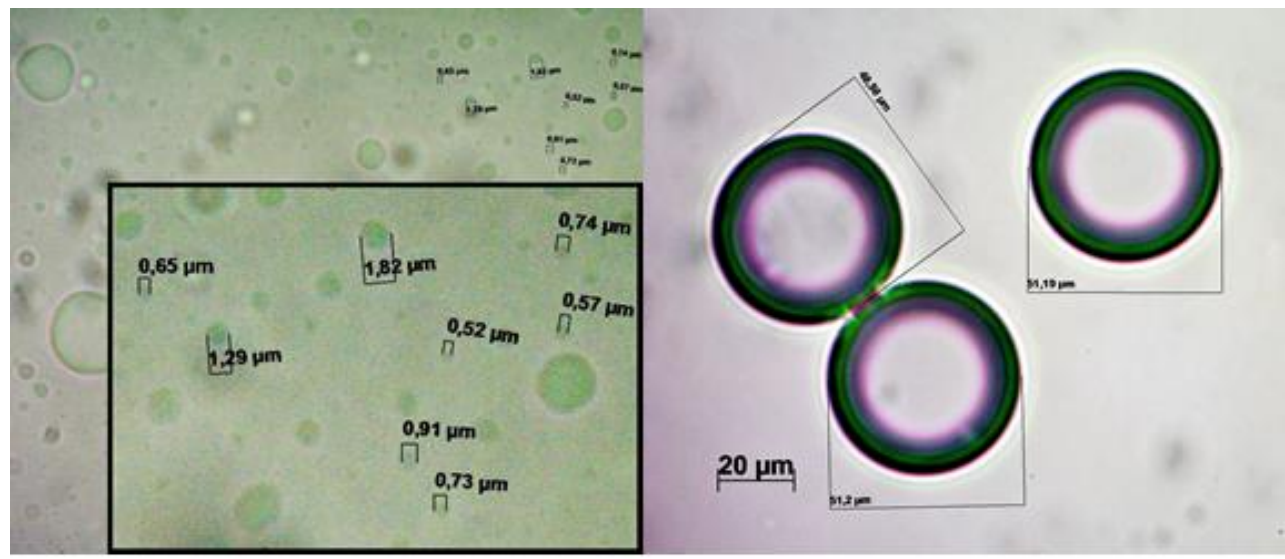

Gambar 3. Deltametrin dalam Formulasi Emulsifiable Concentrate (EC)

Hasil dari fotomikroskop dengan perbesaran 400x terlihat bahwa diperoleh emulsi dengan ukuran diameter rata-rata $1 \mu \mathrm{m}$. Ukuran droplet emulsi ini lebih kecil daripada ukuran formulasi emulsified concentrate komersil yakni 2,5 $\mu \mathrm{m}$. Namun, emulsi yang dihasilkan belum homogen. Hal ini disebabkan karena proses emulsifikasi belum sempurna. Semakin kecilnya ukuran droplet emulsified concentrate menyebabkan semakin mudahnya bahan aktif deltametrin berinteraksi dengan sel target pada OPT sasaran. Selain itu juga, dosis aplikasi penyemprotan menjadi lebih efisien sehingga bisa mereduksi residu pestisida di lingkungan.

\section{Karakterisasi FTIR}

Hasil karakterisasi FTIR bahan aktif deltametrin menunjukkan puncak spektrum bromida alifatik $\mathrm{C}$-Br pada $530,73 \mathrm{~cm}^{-1}$, Regang $\mathrm{C}=\mathrm{C}$ ulur dengan intensitas medium pada $1640,12 \mathrm{~cm}^{-1}$. Gugus $\mathrm{C}=\mathrm{N}$ yang merupakan gugus utama pada deltametrin muncul pada peak $2259,64 \mathrm{~cm}^{-1}$, diikuti oleh regang $\mathrm{C}=\mathrm{O}$ aromatik pada $1715,85 \mathrm{~cm}^{-1}$. Adapun $\mathrm{C}-\mathrm{H}$ regang metil simetrik muncul pada $2876,64 \mathrm{~cm}^{-1}$ dan $=\mathrm{C}-\mathrm{H}$ regang pada $3004,90 \mathrm{~cm}^{-1}$. Spektrum yang sama ditunjukkan untuk deltametrin dalam formulasi Emulsifiable Concentrate (EC). Hasil yang sama ditunjukkan juga spektrum FTIR yakni $=\mathrm{C}-\mathrm{H}$ regang $3143,40 \mathrm{~cm}^{-1}, \mathrm{C}-\mathrm{H}$ regang $3008,41 \mathrm{~cm}^{-1}$. Peak $\mathrm{C}=\mathrm{N}$ ditemukan pada 2360,44 $\mathrm{cm}^{-1}$. Regang C-O ditemukan pada $1068,37 \mathrm{~cm}^{-1}$ sedangkan regang $\mathrm{C}-\mathrm{Br}$ pada $659,54 \mathrm{~cm}^{-1}[6]$.

Berdasarkan konfirmasi spektrum FTIR menunjukkan tidak ada perbedaan spektrum FTIR antara bahan aktif deltametrin dengan deltametrin dalam formulasi Emulsifiable Concentrate (EC). Hal ini menunjukkan bahwa teknologi formulasi insektisida deltametrin dalam bentuk Emulsifiable Concentrate (EC) tidak mengubah bahan aktif insektisida tersebut. Proses emulsifikasi yang melibatkan surfaktan dan kosurfaktan bersifat sebagai zat aktif permukaan yakni menurunkan tegangan permukaan pelarut sehingga ketidakstabilan emulsi dapat diperkecil.

\section{KESIMPULAN}

Formulasi Emulsifiable Concentrate (EC) pestisida sebagai salah satu formulasi insektisida deltametrin dilakukan menggunakan kombinasi surfaktan Tween 80 dan kosurfaktan Poly Etilen Glikol (PEG) 400 dengan perbandingan 20\%:80 $\%$. Kombinasi ini tipe emulsi o/w dengan nilai Hydrophylic-Lipophylic Balance (HLB) sebesar 
13,48. Rata-rata ukuran diameter droplet emulsi sebesar $1 \mu \mathrm{m}$. Proses emulsifikasi tidak menyebabkan perubahan pada bahan aktif deltametrin. Perlu dilakukan karakterisasi lebih lanjut mengenai kestabilan Emulsifier Concentrate (EC) yang terbentuk serta adanya pengembangan formulasi baru insektisida deltametrin ramah lingkungan.

\section{DAFTAR PUSTAKA}

[1] Rehman, H., Aziz, A. T., Saggu, S., Abbas, Z. K., Mohan, A., \& Ansari, A. A. (2014). Systematic review on pyrethroid toxicity with special reference to deltamethrin. Journal of entomology and zoology studies, 2(6), 60-70.

[2] Gadhave, A. (2014). Determination of hydrophilic-lipophilic balance value. Int. J. Sci. Res, 3(4), 573-575.

[3] Sharma, P., Jan, M., \& Singh, R. (2013). Deltamethrin toxicity: A review. Ind J Biol Stud Res, 2(2), 91-107.

[4] Lhoste, J. (1982). Deltamethrin monograph. Roussel Uclaf.

[5] McClements, D. J., Decker, E. A., \& Weiss, J. (2007). Emulsion-based delivery systems for lipophilic bioactive components. Journal of food science, 72(8).

[6] Cycoń, M., Żmijowska, A., \& Piotrowska-Seget, Z. (2014). Enhancement of deltamethrin degradation by soil bioaugmentation with two different strains of Serratia marcescens. International Journal of Environmental Science and Technology, 11(5), 1305-1316.

[7] Rao, T. N., Patrudu, T. B., Babu, K. R., Reddy, E. S., \& Apparao, K. (2014). A Novel Method for Determination of Deltamethrin Residues in Aquatic Tox Medium followed by Gas Chromatography Mass Spectrometry Method. International Journal of Pure and Applied Sciences and Technology, 22(1), 27.

[8] Sharma, K. K., Gupta, S., \& Handa, S. K. (1997). Fourier transform infrared spectroscopic determination of cypermethrin and deltamethrin in emulsifiable concentrate formulations. Talanta, 44(11), 2075-2079.

[9] Wahyuningsih, I., \& Putranti, W. (2015). Optimasi Perbandingan Tween 80 dan Polietilenglikol 400 pada Formula Self Nanoemulsifying Drug Delivery System (SNEDDS) Minyak Biji Jinten Hitam. Pharmacy, 12(2).

[10] World Health Organization. 1990. Deltamethrin. International Programme on Chemical Safety, Swiss

[11] Kamali, S. R. (2008). Distrubusi insektisida deltametrin pada tanaman cabai besar (Capsicum annum L.) (Thesis, Universitas Gadjah Mada). 